\title{
Bicornuate Uterus with Successful Pregnancy Outcome
}

\author{
Dr. Sajana Gogineni ${ }^{1}$, Dr. K. Jaya Prada Devi ${ }^{2}$, Dr. Venkata Sujatha Vellanki ${ }^{3}$, \\ Dr. Sravanthi $\mathrm{M}^{4}$, Dr. Dharmaja. $\mathrm{D}^{5}$, \\ Professor \& HOD ${ }^{1}$, Assoc. Professor ${ }^{2}$, Professor $^{3}$, Postgraduate ${ }^{4,5}$ \\ 1,2,3,4,5 (Dept of OBG, Dr. Pinnamaneni Siddhartha Institute of Medical Sciences \& Research Foundation, \\ Chinoutpalli, Gannavaram, Krishna Dt)
}

\begin{abstract}
The prevalence of uterine malformations in general population is around 7-8\%. Abnormal fusion of mullerian ducts in embryonic life results in a variety of malformations. Here we report a case of bicornuate uterus where pregnancy was carried till 38weeks with good outcome. Initially diagnosis was made by Ultrasound, which was confirmed intra operatively by exteriorizing the uterus.
\end{abstract}

Keywords: Bicornuate uterus, mullerian anomaly

\section{Introduction}

Abnormal fusion of the para-mesonephric duct (mullerian duct) during embryonic life result in a variety of congenital uterine malformations, such as uterus didelphys, uterus bicornis bicollis, uterus bicornis unicollis, uterus subseptae, uterus arcuatus, uterus unicornis. The bicornuate uterus accounts for approximately $10 \%$ of the mullerian anomalies. Women with bicornuate uterus have no extra uterine infertility issues ${ }^{1}$. The uterine malformations are known to be associated with spontaneous miscarriages, intrauterine growth restriction, preterm deliveries, preterm prelabour rupture of membranes, breech presentation and increased rate of caesarean delivery. The rates of spontaneous abortion and premature delivery have been reported to reflect the degree of non fusion of the horns. The common complications and adverse reproductive outcomes associated with bicornuate uterus are recurrent pregnancy loss $(25 \%)^{1}$, preterm birth $(15-25 \%)^{3}$ and cervical insufficiency $(38 \%)^{4}$. We report a case of bicornis unicollis pregnancy which was carried till 38 weeks and had a good outcome.

\section{Case report}

A 20 year old second gravida, presented to the antenatal clinic at Dr. Pinnamaneni Siddhartha Institute of Medical Sciences with 2 months of amennorhoea with a history of term Intrauterine death in the previous pregnancy. Early ultrasound detected a bicornuate uterus with pregnancy in right horn. Per speculum examination showed one cervix. She had A prophylactic cervical encerclage was done at 14weeks of gestation.

She had an uneventful antenatal period. At $38 \mathrm{wk}$ cervical stitch removed. In view of previous term Intrauterine death \& present unengaged head at 39 weeks 5 days with cord round the neck patient was posted for elective LSCS.

Intra operative findings: Bicornuate uterus with pregnancy in well developed right horn seen. (Figure 1,2)Left horn measures $10 \times 12$ centimeters. A live female child weighing 2.4kilograms was delivered.(Figure3) Placenta is located posteriorly in upper segment of right horn. The findings were confirmed by exteriorizing the uterus and noting the communication between the two cavities and single cervix. The patient had an uneventful post operative period and discharged on $7^{\text {th }}$ post operative period.

\section{Discussion}

The prevalence of uterine anomalies is $7-8 \%{ }^{1}$. And now because of better availability of diagnostic modalities, better detection of such anomalies is possible.

Bicornuate uterus is a congenital uterine anomaly that results from defective lateral fusion of the paramesonephric ducts at about the tenth week of intrauterine life around the fundus. A bicornuate uterus consists of two symmetric cornua that are fused caudad, with communication of the endometrial cavities- most often at the level of the uterine isthmus. In a partial bicornuate unicollis uterus the intervening cleft is of variable length.

Bicornuate uterus has been reported to have the highest prevalence of cervical incompetence among mullerian anomalies ${ }^{4}$. Prophylactic placement of cervical cerclage in selected patients has been reported to increase fetal survival rates ${ }^{5}$. Most widely accepted classification was given by subcommittee of the American fertility society(now the American society of reproductive medicine) in $1988^{6}$. Bicornuate uteri belong to class 4 
of this classification. Toaff et al described nine subtypes of septate and bicornuate uteri with communicating cavities ${ }^{7}$.

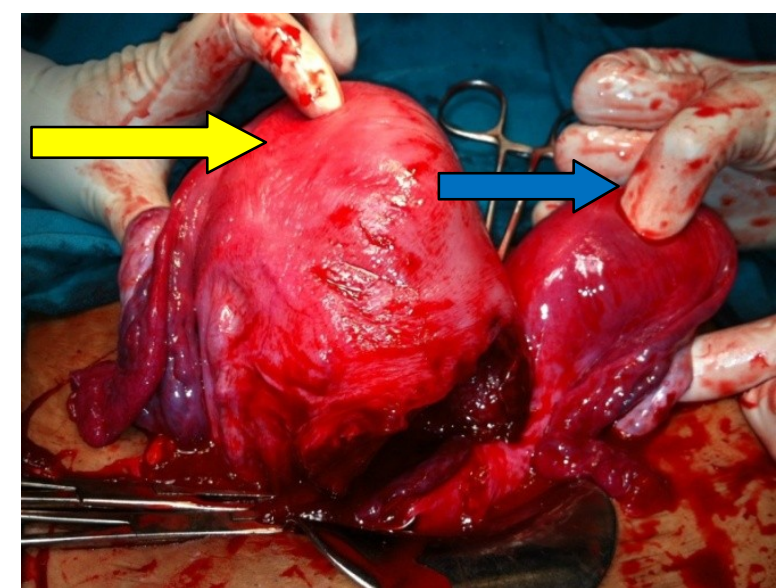

Figure I: Intraoperative picture yellow showing right horn\& blue arrow showing left horn bicornuate uterus before closing the uterine cavity

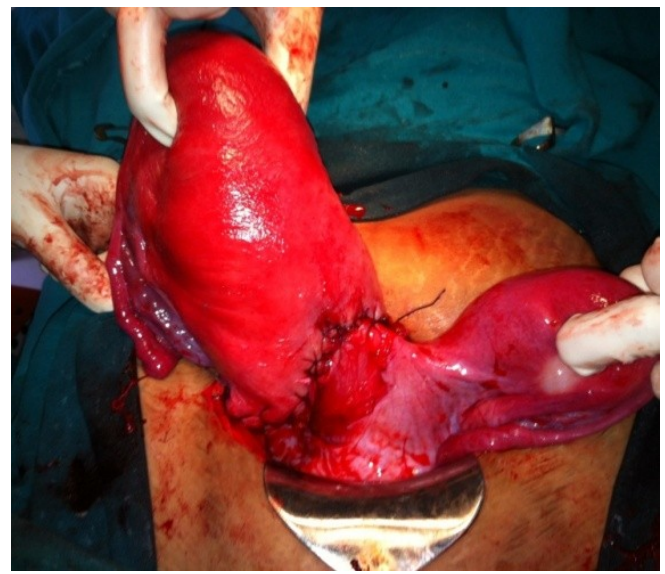

igure 2: Intraoperative picture showing bicornuate uterus after closing the uterine cavity

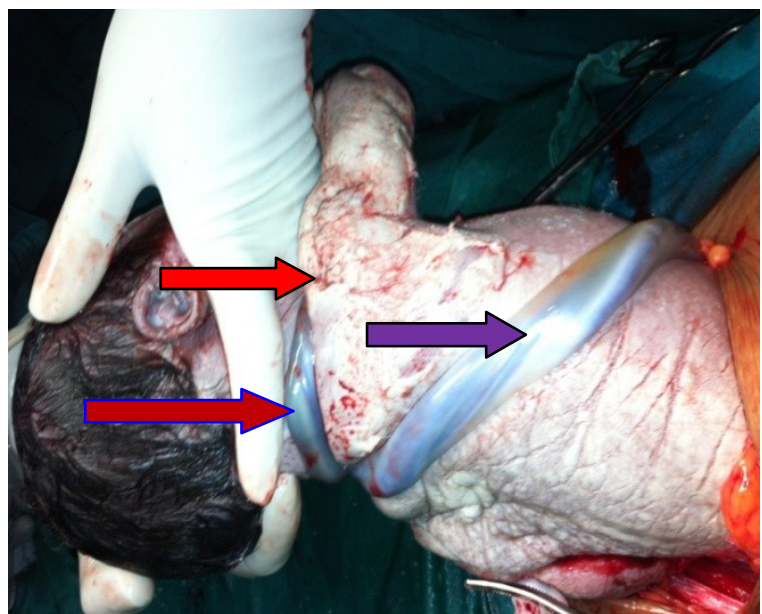

Figure 3: Showing baby cord round the neck three times 


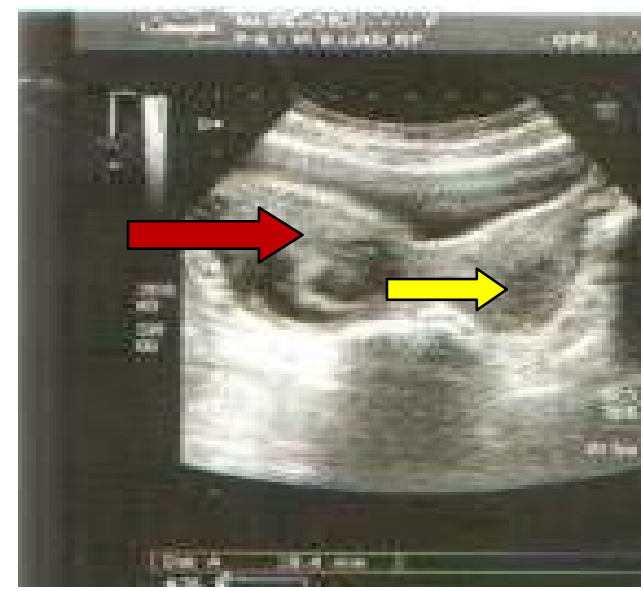

Figure 4: ultrasound showingbicornuate uterus and pregnancy in the right horn Red arrow showing right horn and yellow arrow showing left horn.

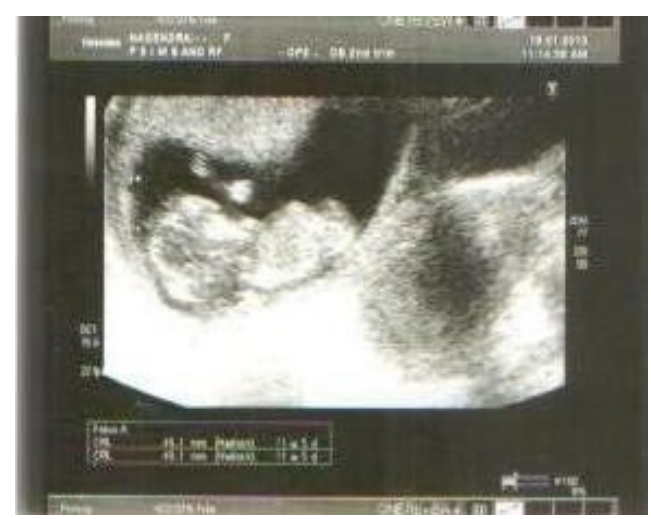

Figure 5: Ultrasound showing bicornuate uterus

\section{Conclusion}

The present case was diagnosed in an early first trimester scan. Awareness of this condition is necessary to make a diagnosis and improve pregnancy outcome. Early diagnosis and good antenatal care help to improve the outcome in a bicornuate uterus.

\section{References}

[1]. Lin PC. Reproductive Outcomes in Women with Uterine Anomalies. J Women Health (Larchmt) 2004; 13(1) : 33-9.

[2]. Simon C, Martinex I, Pardo F, Tartajada M, Iellicor A. Mullerian defects in women with normal reproductive outcome. Fertil Steril1991; 561192-3.

[3]. Heinonen PK, Saarikoski S, Pystynen P. Reproductive performance of women with uterine anomalies. An evaluation of 182 cases. Acta Obstet Gynecol Scand 1982; 61: 157-162.

[4]. Golan A, langer R, Wexler S, Seceg E, Niv D, Menachem PD. Cervical Cerclage: its role in the pregnant anomalous uterus. Int J Fertill 1990;35:164-170.

[5]. Blum M. Prevention of spontaneous abortion by cervical suture of the malformed uterus. Int surg 1977;62:213-215.

[6]. The American fertility society classifications of adnexal adhesions, distal tubal obstruction, tubal occlusion secondary to tubal ligation, tubal pregnancies, mullerian anomalies and intrauterine adhesions. Fertil Steril 1988;49:944-955.

[7]. Toaff ME, lev-ToaffAS, Toaff R. communicating uteri:review and classification with introduction of two previously reported unreported types. Fertil Steril 1984;41:661-679. 